\title{
Do we publish what we preach? Analysis of the European Society for Surgery of the Shoulder and Elbow Congress publication rates
}

\author{
J. Miquel ${ }^{1 *}$ S. Fernández-Muñoz ${ }^{1}$, F. Santana ${ }^{2}$ and C. Torrens ${ }^{2}$
}

\begin{abstract}
Background: Scientific congresses have become the most expedient method to communicate novel findings on any research topic. However, an important question is whether this information will be published in peer-reviewed journals. Our aim was to determine the publication rate of the abstracts presented at the European Society for Surgery of the Shoulder and Elbow Congress and analyze factors that may influence this rate.

Methods: A total of 398 abstracts reported in the Abstract Book from the 2008 European Society for Surgery of the Shoulder and Elbow Congress were examined and categorized by oral and poster presentations, topic, and the number of authors listed. A search in PubMed and Google Scholar for subsequent peer-reviewed publications was performed in September 2015. The time to publication after the meeting had been held; the type of journal and its impact factor at the time to publication were recorded for those abstracts that reached peer-reviewed journal publication.

Results: The overall publication rate for the 2008 European Society for Surgery of the Shoulder and Elbow oral and poster presentations was $45.20 \%$ after 7 years. The mean time to publication was 18.53 months, and the mean impact factor value was 2.32. Oral presentations were significantly better represented in journals than posters (64.40 vs. $35.40 \%, p<0.001)$. Abstracts with a greater number of authors listed had better publication rates $(p<0.001)$.

Conclusion: Less than half of the oral presentations and posters at the 21 st European Society for Surgery of the Shoulder and Elbow Congress were published in peer-reviewed journals. Oral presentations with a higher number of authors had an increased likelihood of being published.
\end{abstract}

Keywords: Publication rates, SECEC congress, Abstracts, Podium presentation, Poster presentation

\section{Background}

The main goal for researchers with scientific findings is to share their data with the scientific community. New findings or novel techniques are usually first presented to medical societies at congresses or meetings. However, publication in peer-reviewed journals represents the gold standard for disseminating scientific data across the scientific community, as copious data related to a study cannot be covered in-depth at the podium or in a poster presentation.

\footnotetext{
* Correspondence: joanmiquelnoguera@hotmail.com

${ }^{1}$ Orthopaedics \& Trauma Department, Consorci Sanitari de l'Anoia, Avinguda Catalunya 11, 08700 Igualada, Spain

Full list of author information is available at the end of the article
}

Interest in a meeting's or a society's publication rate has recently risen, as it represents an indicator of the degree and quality of the scientific society's activity. The publication rate has become a tool for determining the scientific level of the congress. Several orthopedic and trauma surgery societies have published their congress or meeting publication rates [1-22]. Among shoulder and elbow societies, only the Shoulder and Elbow Sessions of the American Academy of Orthopedic Surgery has published the abstract publication rates of the congress [23]. In 2015, the 26th European Society for Surgery of the Shoulder and Elbow (SECEC) Congress celebrated the most successful congress this 
society has ever had relative to the number of participants. The participants were from more than 50 countries, and the number of submitted abstracts was equally notable [24]. Therefore, the stature of the SECEC justifies a systematic study of its abstracts. P. Hughes and colleagues presented a poster at the 21st SECEC Congress (2008) compared the publication rates of the abstracts presented at the British Elbow and Shoulder Society to those presented at the SECEC. This report is still the only reference to the SECEC Congress publication rate. Therefore, little is known about the fate of abstracts after presentation in an SECEC Congress.

The purpose of this study was to report the SECEC publication rate in peer-reviewed journals and to analyze the characteristics of the abstracts that achieved peerreviewed journal publication.

\section{Methods}

Papers reported in the Final Program from the 21st SECEC Congress (2008) were included in this study to determine peer-review process survivorship. The Final Program from 2008 was available online, and the time to expected publication was set at 7 years.

All abstracts were investigated using the PubMed and Google Scholar databases in September 2015 to identify any corresponding published articles in the journals listed in the databases. The search parameters included the first author along with the first broad keyword appearing in the abstract title. When not successful, the search was followed by a search for all subsequent authors using the same parameters before declaring an abstract unpublished. An abstract was considered "published" based on the following criteria: when congress papers in the Final Program and their publication in journals could be matched with the same or a similar title or when a coincidence of authors in a title that referred to the same topic was found. In the case of multiple publications per abstract, the time to publication closest to the congress was used. When a publication occurred before the congress was held, the abstract was categorized as "published" if the title of the paper could be attributed to the original SECEC Congress abstract. All these criteria were previously established to quantify congress publication rates [19].

A total of 398 abstracts reported in the 2008 SECEC Congress Final Program were classified based on several characteristics to determine which of these abstracts had a greater likelihood of being published. The number of authors listed and the time span to publication (in months) were obtained by calculating the time from September 2008 to the month of journal publication. Papers were categorized by topic, including the elbow, proximal humeral fractures, the rotator cuff, degenerative shoulder pathologies/arthroplasties, instability, the clavicle and AC joint, miscellaneous/basic science, and tips and tricks/new techniques. The peer-reviewed journal and its impact factor at the time to publication were recorded for those abstracts that achieved peer-reviewed journal publication using the Journal Citation Reports ${ }^{\circ}$ (Clarivate Analytics, 2017) [25].

The statistical analysis was performed using the SPSS 18.0 package (SPSS Inc., Chicago, IL). A descriptive analysis was initially performed. A non-parametric Wilcoxon test was also performed to compare groups with an asymmetric distribution, while Spearman's correlation was used to evaluate the associations between groups. A chi-squared test was performed to evaluate the association between dichotomous variables, such as the publication of the abstract before vs. after the congress.

Confidence intervals were estimated at $95 \%$ of the estimators, and the differences were considered significant at $p<0.05$.

\section{Results}

A total of 522 abstracts were submitted for oral or poster presentations in this congress, and 398 were accepted for presentation at the 21st SECEC Congress. Thus, $76.24 \%$ of the abstracts submitted were accepted for either oral or poster presentations. Regarding oral presentations, $135(25.86 \%)$ of the total abstracts submitted were accepted while 263 abstracts (50.38\%) were accepted as poster presentations.

Of the 398 abstracts accepted for the 21st SECEC Congress, 135 (33.92\%) were categorized as podium presentations, while $263(66.08 \%)$ were poster presentations. Abstracts that survived the peer-review process were published in 25 different journals, with a mean impact factor value of $2.32(0.18-7.33)$. The mean time span to publication was 18.53 months $(-28$ months to 77 months). Twenty-five abstracts were published before the SECEC Congress was celebrated, with a mean of 18.5 months ( -28 months to 0 months) in advance. The mean number of authors listed on the abstracts was 4.05 (1-7). The classification relative to the topic of the paper is shown in Table 1.

The overall publication rate was $45.20 \%$ after 7 years. Oral presentations were significantly better represented in journals than posters $(64.40$ vs. $35.40 \%, p<0.0001)$. A clear majority of the abstracts that survived the peerreview process $(172 / 180,95.55 \%)$ were published within 4 years of the congress presentation.

A significant correlation was observed between the number of authors and the publication rates. Abstracts with a greater number of authors (more than three authors) tended to have a better chance of being published $(p<0.0001)$, even for poster presentations $(p=0.03)$. Moreover, $74 \%$ of posters with three or fewer authors never achieved subsequent journal 
Table 1 Distribution of abstracts according to topic, and their publication rate

\begin{tabular}{llll}
\hline Abstract topic & Number of abstracts & Percentage of abstracts & Publication rate (\%) \\
\hline Elbow & 50 & 12.6 & 42 \\
Proximal humeral fractures & 42 & 10.6 & 33.3 \\
Rotator cuff & 69 & 17.3 & 39.1 \\
Shoulder degenerative/arthroplasty & 38 & 9.5 & 55.3 \\
Instability & 37 & 9.3 & 48.6 \\
Clavicle and AC joint & 17 & 4 & 43.8 \\
Miscellaneous/basic science & 98 & 24.7 & 50 \\
Tips and tricks/new techniques & 47 & 11.8 & 46.8 \\
Total & 398 & 100 & 45
\end{tabular}

publication. The number of authors had no effect on the impact factor obtained in journals for those abstracts that were subsequently published (Spearman's correlation test $0.06,95 \%$ confidence interval -0.1 to $0.21)$. The topic of the presentation was not correlated with the probability of publication $(p=0.50$, Table 1). Abstracts with a longer time to publication in a peer-review journal were published in journals with a higher impact factor $(p=0.03)$. Among those papers that obtained journal publication through a peer-review process, studies published before the SECEC Congress was held exhibited a lower impact factor in journals (1.86) than those published in journals after the congress $(2.38, p=0.006)$ (Fig. 1). Thus, a correlation was found between the impact factor and the time to publication (0.24; Spearman correlation test). However, posters were more represented than oral presentations among papers published beforehand (18 posters, 6 oral presentations, $p=0.03)$. In the adjusted model analysis, the impact factor for abstracts published beforehand continued to be 0.5 points less than those that were published after the congress, despite the influence of the number of posters among those works $(p=0.04)$.

\section{Discussion}

The present study determined that almost half of the podium or poster presentations in the 21st SECEC Congress survived the peer-review process, which is believed to be the gold standard for communicating scientific data. However, the type of presentation (oral and poster presentation) and a greater number of authors listed were related to the possibility of subsequent publication in journals.

The SECEC Congress has become to be an important meeting for shoulder and elbow specialists worldwide. Interest in this European congress is increasing yearly [24]. However, little information is known about the quality of this scientific forum. This congress focuses on the shoulder and elbow subspecialty, but no previous paper has reported this specialty congress publication rate. Only one previous paper reported subspecialty publication rates for the 2001 American Academy of Orthopedic Surgeons Meeting, with a podium and poster publication rate of $53 \%$ [23]. The SECEC publication rate is comparable to other international congresses and even to general congresses for trauma and orthopedics $[1-3,6,7,13,15,18,23]$ or specialty meetings $[4,5,8-12,14,16,17,19-22]$ (Table 2 ).

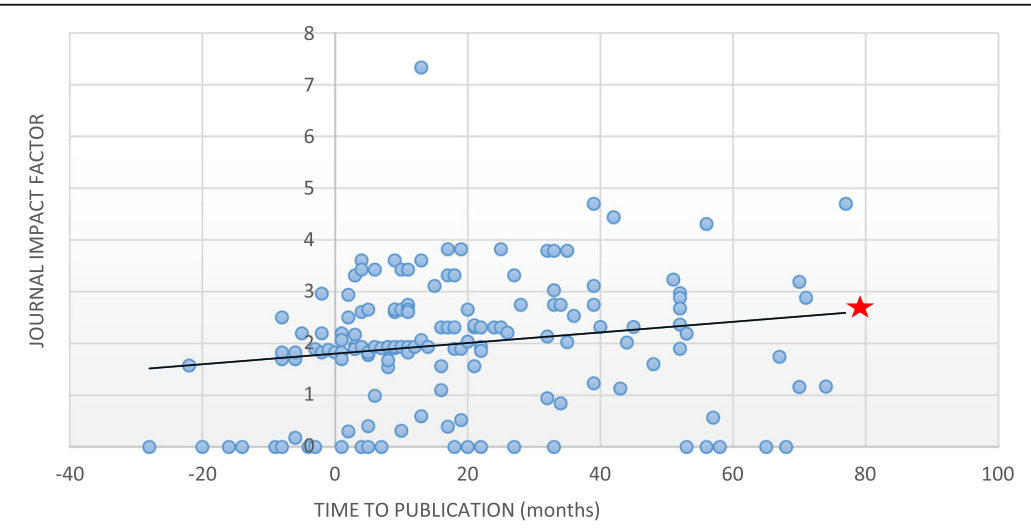

Fig. 1 Correlation between time span to publication and impact factor (IF) obtained. $\boldsymbol{t}$ The Spearman correlation between the time to publication and the impact factor of the journal was 0.24 (confidence interval 95\% 0.09 to 0.39) 
Table 2 Comparison of different congresses publication rates, ordered alphabetically

\begin{tabular}{|c|c|c|c|c|c|}
\hline Congress & Year & GLOBAL PR & PODIUM PR & POSTER PR & $\begin{array}{l}\text { Observational period } \\
\text { (minimum) }\end{array}$ \\
\hline AAHKS [22] & $1996-2001$ & NR & NR & $47 \%$ & $?$ \\
\hline AAHKS [14] & 1996-2001 & NR & $58 \%$ & NR & $?$ \\
\hline AAOS [2] & 1996 & $34 \%$ & & & $?$ \\
\hline AAOS [1] & 2001 & $49 \%$ & $47 \%$ & $52 \%$ & 5 years \\
\hline $\begin{array}{l}\text { AAOS Shoulder } \\
\text { and Elbow Sessions [23] }\end{array}$ & 1999-2004 & $58 \%$ & $66 \%$ & $51 \%$ & 3 years \\
\hline $\begin{array}{l}\text { AANA } \\
\text { AOSSM [21] }\end{array}$ & 1990-1993 & $\begin{array}{l}68.1 \% \\
50.9 \%\end{array}$ & $N R$ & $N R$ & $?$ \\
\hline AOSSM [10] & 2006-2010 & $67.1 \%$ & $73.3 \%$ & $56.9 \%$ & 3 years \\
\hline EPOS [14] & 2006-2008 & $36.7 \%$ & $?$ & $?$ & 5 years \\
\hline $\begin{array}{l}\text { German Society Orthopedics } \\
\text { and Trauma Surgery [18] }\end{array}$ & 2003 & $36 \%$ & $?$ & $?$ & 5 years \\
\hline ISAKOS [4] & $\begin{array}{l}1997 \\
1999\end{array}$ & $\begin{array}{l}34.6 \% \\
39.3 \%\end{array}$ & NR & NR & 4 years \\
\hline OTA [16] & 1990-1995 & $64 \%$ & NR & NR & $?$ \\
\hline OTA [17] & 1994-1998 & & $67 \%$ & $52 \%$ & $?$ \\
\hline POSNA [8] & 1991-1994 & & $53 \%$ & & 4 years \\
\hline SECEC & 2008 & $45.2 \%$ & $64.4 \%$ & $35.4 \%$ & 7 years \\
\hline Spine Society of Europe [19] & $2000-2003$ & $37.8 \%$ & 48.4 & 31.3 & 5 years \\
\hline $\begin{array}{l}\text { Spine Specialty Society } \\
\text { (NASS, SRS, ISSLS) [20] }\end{array}$ & $\begin{array}{l}1990-1992 \text { (NASS) } \\
1991-1993 \text { (SRS) } \\
1991-1993 \text { (ISSLS) }\end{array}$ & $\begin{array}{l}40 \% \\
47 \% \\
45 \%\end{array}$ & NR & NR & 4 years \\
\hline
\end{tabular}

GLOBAL PR Global Publication Rate, PODIUM PR Podium Publication Rate, POSTER PR Poster Publication Rate, AAHKS American Academy of Hip and Knee Surgery, AAOS American Academy of Orthopedic Surgeons, AANA Arthroscopy Association of North America, AOSSM American Orthopedic Society of Sports Medicine, EPOS European Pediatric Orthopedic Society, ISAKOS International Society of Arthroscopy, Knee Surgery \& Orthopedic Sports Medicine, ISSLS International Society for the Study of Lumbar Spine, NASS North American Spine Society, OTA Orthopedic Trauma Association, POSNA Pediatric Orthopedic Surgery of North America, SECEC

European Society for Surgery of the Shoulder and the Elbow, SRS Scoliosis Research Society

Podium and poster presentations had different publication rates. Poster presentations are commonly thought be published at a lower rate than podium presentations, as podium presentations are typically believed to consist of studies with greater scientific value [17]. Although a significant difference exists between podium and poster presentations, authors presenting poster papers should not feel discouraged by the peer-review publication process because the SECEC poster publication rates are not low.

Previous papers studying different congresses (Orthopedics Research Society Meeting, International Society of Arthroscopy, Knee Surgery and Orthopedic Sports Medicine, American Academy Orthopedic Surgeons Meeting, Australian Orthopedic Association Annual Scientific Meeting, and American Orthopedic Society for Sports Medicine and the Arthroscopy Association of North America Meeting) have suggested that more than $90 \%$ of the published abstracts achieve journal publication within 4 years following the congresses [2, 4, 6, 7, 12, 21]. Based on the present paper's findings, it might be feasible to extend the mean expected time to publication to more than 4 years, as some abstracts (nearly $5 \%$ ) are published 7 years after congress presentations. This finding could contribute to increasing some congress publication rates, as previous reports have projected the publication of congress abstracts within a shorter period after meetings were held $[2,3,6,7,12,18]$.

A new challenge for scientific congress committees is the problem of previously published papers being presented as new abstracts at the meetings. Several papers have reported this problem in various congresses $[2,5,9,13,14,23]$. Preventing plagiarism of their work may explain the authors' inclination to publish prior to being presented at the congress. However, papers published prior to the congress tend to be published in journals with a lower impact factor, regardless of the type of presentation (abstracts or posters). Moreover, publishing in high impact factor journals may represent a lengthy amount of work for authors, as the delay in publication seems to have a positive effect on the impact factor obtained. The correlation between the time to publication and the impact factor was weak, as coefficient values range from 0.20 to 0.39 in a Spearman's correlation are typically considered as weak. 
The abstract topic had no influence on the journal peerreview process at the 21st SECEC Congress. This finding seems to be different from the findings from other shoulder and elbow congresses, in which the abstract topic plays a role in the probability of publication in a journal [23].

Various reasons have been proposed to explain the disparity between congress presentations and journal publications. A major barrier indicated by authors is the lack of time [26]. This may explain why in the present study, abstracts with a greater number of authors listed were more likely to be published than those with fewer authors. Moreover, most of the unpublished abstracts have never been submitted to the peer-review process [26, 27]. This study had several limitations. One limitation is that this paper analyzed only one SECEC Congress. Furthermore, the reasons for nonpublication were not studied, and the number of abstracts that were not submitted for publication or those that did not survive the peer-review process remains unknown. The strengths of the present study lie in the number of abstracts analyzed, which included both oral presentations and poster abstracts, and the long time to publication.

\section{Conclusions}

In conclusion, less than half of the oral presentations and posters at the 21st SECEC Congress were published in peer-reviewed journals. The SECEC Congress is among the orthopedic specialty meetings with the highest publication rates. Although authors may consider posters as lower-level scientific communications, they have a reasonable publication rate.

\begin{abstract}
Abbreviations
AAHKS: American Academy of Hip and Knee Surgery; AANA: Arthroscopy Association of North America; AAOS: American Academy of Orthopedic Surgeons; AC: Acromioclavicular; AOSSM: American Orthopedic Society of Sports Medicine; EPOS: European Pediatric Orthopedic Society; GLOBAL PR: Global Publication Rate; ISAKOS: International Society of Arthroscopy, Knee Surgery \& Orthopedic Sports Medicine; ISSLS: International Society for the Study of Lumbar Spine; NASS: North American Spine Society; OTA: Orthopedic Trauma Association; PODIUM PR: Podium Publication Rate; POSNA: Pediatric Orthopedic Surgery of North America; POSTER PR: Poster Publication Rate; SECEC: European Society for Surgery of the Shoulder and Elbow; SRS: Scoliosis Research Society
\end{abstract}

\section{Acknowledgements}

We thank Sergi Mojal for assistance with the statistical analyses.

\section{Funding}

The authors declare the study had no external funding.

\section{Availability of data and materials}

The datasets used and/or analyzed during the current study are available from the corresponding author on reasonable request.

\section{Authors' contributions}

JM conceived the study, collected data, and was the lead author on the manuscript. He was the main designer of the study. SF-M assisted in data collection and was the main compiler of the data. FS participated in the design of the study and managed the statistical analysis. CT participated in the design of the study and helped draft the manuscript. He reviewed all the steps of the entire manuscript. All authors read and approved the final manuscript.
Ethics approval and consent to participate

Not applicable.

\section{Consent for publication}

Not applicable.

\section{Competing interests}

The authors declare that they have no competing interests.

\section{Publisher's Note}

Springer Nature remains neutral with regard to jurisdictional claims in published maps and institutional affiliations.

\section{Author details}

'Orthopaedics \& Trauma Department, Consorci Sanitari de I'Anoia, Avinguda Catalunya 11, 08700 Igualada, Spain. ${ }^{2}$ Orthopaedics \& Trauma Department, Parc de Salut Mar. Barcelona, Passeig Marítim 25-29, 08003 Barcelona, Spain.

Received: 8 February 2017 Accepted: 13 July 2017

Published online: 24 July 2017

\section{References}

1. Bhandari M, Devereaux PJ, Guyatt GH, Cook DJ, Swiontkowski MF, Sprague S. An observational study of orthopaedic abstracts and subsequent full-text publications. J Bone Joint Surg Am. 2002;84(4):615-21.

2. Daluiski A, Kuhns CA, Jackson KR, Lieberman JR. Publication rate of abstracts presented at the annual meeting of the Orthopaedic Research Society. J Orthop Res. 1998;16(6):640-45.

3. Donegan DJ, Kim TW, Lee GC. Publication rates of presentations at the annual meeting of the American Academy of Orthopaedic surgeons. Clin Orthop Relat Res. 2010;468(5):1428-35. doi:10.1007/s1 1999-009-1171-5.

4. Eck JC. Publication rates of abstracts presented at biennial meetings of the International Society of Arthroscopy, knee surgery and Orthopaedic sports medicine. Knee Surg Sports Traumatol Arthrosc. 2005;13(5):426-9. doi:10. 1007/s00167-004-0559-8.

5. Gavazza JB, Foulkes GD, Meals RA. Publication pattern of papers presented at the American Society for Surgery of the Hand annual meeting. J Hand Surg Am. 1996;21(5):742-5.

6. Hamlet WP, Fletcher A, Meals RA. Publication patterns of papers presented at the annual meeting of the American Academy of Orthopaedic surgeons. J Bone Joint Surg Am. 1997;79(8):1138-43.

7. Harris IA, Mourad MS, Kadir A, Solomon MJ, Young JM. Publication bias in papers presented to the Australian Orthopaedic Association annual scientific meeting. ANZ J Surg. 2006;76(6):427-31. doi:10.1111/j.1445-2197. 2006.03747.x.

8. Jackson KR, Dalusiki A, Kay RM. Publication of abstracts submitted to annual meeting of the pediatric Orthopaedic Society of North America. J Pediatr Orthop. 2000;20:2-6.

9. Jasko JJ, Wood JH, Schwartz HS. Publication rates of abstracts presented at annual musculoskeletal tumor society meetings. Clin Orthop Relat Res. 2003; 415:98-103. doi:10.1097/01.blo.0000093902.12372.76.

10. Kinsella SD, Menge TJ, Andersons AF. Publication rates of podium versus poster presentations at tha American Orthopaedic Society for Sports Medicine meetings:2006-2010. Am J Sports Medicine. 2015;43(5):1255-9. doi:10.1177/0363546515573939.

11. Kleine-Konig MT, Schulte TL, Gosheger G, Rödl R, Schiedel FM. Publication rate of abstracts presented at European pediatric Orthopaedic society annual Metings, 2006 to 2008. J Pediatr Orthop. 2014;34(6):e33-8. doi:10. 1097/BPO.

12. Kleweno CP, Bryant WK, Jacir AM, Levine WN, Ahmad CS. Discrepances and rates of publication in orthopaedic sports medicine abstracts. Am J Sports Med. 2008:36(10):1875-9. doi:10.1177/0363546508319054.

13. Kwong $Y$, Kwong FN, Patel J. Publication rate of trauma abstracts presented at an international Orthopaedic conference. Injury. 2007;38(7):745-9. doi:10. 1016/j.injury.2006.07.002.

14. Lloyd EW, Geller JA, lorio R, Yoon RS, Huo MM. Publication rates of scientific presentations at the American Association of hip and Knee Surgeons annual meetings from 1996 to 2001. J Arthroplast. 2006;21(6):2-5. doi:10.1016/j.arth. 2006.04.021 
15. Murrey DB, Wright RW, Seiler JG 3rd, Day TE, Scwartz HS. Publication rates of abstracts presented at the 1993 annual academy meeting. Clin Orthop Relat Res. 1999;359:247-53.

16. Nguyen V, Tornetta P 3rd, Bkaric M. Publication rates of the scientific sessions of the OTA (Orthopaedic trauma association). J Orthop Trauma. 1998;12(7):457-9.

17. Preston CF, Bhandari M, Fulkerson E, Ginat D, Koval KJ, Egol KA. Podium versus poster publication rates at the Orthopaedic trauma association. Clin Orthop Relat Res. 2005;437:260-4. doi:10.1097/01.blo.0000167667.80325.61.

18. Schulte TL, Trost M, Osada N, Huck K, Lange T, Gosheger G, et al. Publication rate of abstracts presented at the annual congress of the German Society of Orthopaedics and Trauma Surgery. Arch Orthop Trauma Surg. 2012;132:271-80. doi:10.1007//s00402-011-1398-y.

19. Schulte TL, Huck K, Osada N, Trost M, Lange T, Schmidt C, Gosheger G, Bullmann V. Publication rate of abstracts presented at the annual congress of the spine Society of Europe (years 2000-2003). Eur Spine J. 2012;21:210512. doi:10.1007/s00586-012-2211-5.

20. Wang JC, Yoo S, Delamarter RB. The publication rates of presentations at major spine Speciality society meetings (NASS, SRS, ISSLS). Spine (Phila Pa 1976). 1999;24(5):425-7.

21. Yoo S, Oh G, Wang JC. Publication rates of presentations made at annual meetings of the American Orthopaedic Society for Sports Medicine and the Arthroscopy Association of North America. Am J Orthop (Belle Mead NJ). 2002;31(6):367-9.

22. Yoon RS, Lloyd EW, McGrory B, Bal BS, Macaulay W. Studies presented in poster format at the annual meetings of the American Association of hip and Knee Surgeons: how do they fare in the peer review process? J Arthroplast. 2007;22(6):17-20. doi:10.1016/j.arth.2007.03.010

23. DeMola PM, Hill DL, Abboud JA. Publication rate of abstracts presented at the shoulder and elbow session of the American Academy of Orthopaedic surgery. Clin Orthop Relat Res. 2009;467(6):1629-33. doi:10.1007/s11999-008-0474-2.

24. Gohlke, F. (2016, September). Presidential Newsletter [Letter to SECEC Members].

25. Journal Citation Reports (Clarivate Analytics, 2017). Accessed 19 July 2017.

26. Spraque S, Bhandari M, Devereaux PJ, Swiontkiwski MF, Tornetta P 3rd, Cook $D J$, et al. Barriers to full-text publication following presentation of abstracts at annual orthopaedic meetings. J Bone Joint Surg Am. 2003:85(1):158-63.

27. Weber EJ, Callaham ML, Wears RL, Barton C, Young G. Unpublished research from a medical speciality meeting: why investigators fail to publish. JAMA. 1998;280(3):257-9.

\section{Submit your next manuscript to BioMed Central and we will help you at every step:}

- We accept pre-submission inquiries

- Our selector tool helps you to find the most relevant journal

- We provide round the clock customer support

- Convenient online submission

- Thorough peer review

- Inclusion in PubMed and all major indexing services

- Maximum visibility for your research

Submit your manuscript at www.biomedcentral.com/submit

) Biomed Central 